14

\title{
Структура и пьезоэлектрические свойства микропористых пленок поливинилиденфторида
}

\author{
(С) И.Ю. Дмитриев, И.С. Курындин, В.К. Лаврентьев, Г.К. Ельяшевич
}

Институт высокомолекулярных соединений РАН,

Санкт-Петербург, Россия

E-mail: ivan-dmitriev-email@yandex.ru

(Поступила в Редакцию 31 августа 2016 г.

В окончательной редакции 20 октября 2016 г.)

\begin{abstract}
Разработан метод получения микропористых пленок поливинилиденфторида, характеризующихся высоким содержанием пьезоактивной кристаллической фазы и обладающих развитой рельефной поверхностью. Пористые пленки получены в процессе, основанном на экструзии расплава с последующими изометрическим отжигом и одноосным растяжением. Установлено, что образцы имеют ориентированную ламеллярную структуру, включающую $\alpha$ - и $\beta$-модификации кристаллитов. Исследовано влияние температуры и степени одноосного растяжения отожженных пленок на характеристики полученных пористых образцов: содержание пьезоактивной кристаллической $\beta$-фазы, общую пористость, напряжение пробоя и величину пьезомодуля.
\end{abstract}

Работа проведена при поддержке гранта РФФИ (№ 16-03-00265a) и Проекта совместных исследований PAН и Университета Любляны (Словения) ARRS-BI-RU/16-18-017.

DOI: 10.21883/FTT.2017.05.44394.335

\section{1. Введение}

Разработка подходов к получению пьезопленок нового типа на основе поливинилиденфторида (ПВДФ) и сополимеров винилиденфторида относится к одному из наиболее актуальных направлений в области физики, химии и технологии высокомолекулярных соединений. В последнее десятилетие ПВДФ активно используется в области разработки гибридных электроактивных материалов, в которых пьезоподложка сочетается с другим активным компонентом, что открывает возможность получения на базе такого материала целого спектра перспективных устройств нового поколения, таких как пьезобиосенсоры, пьезосуперконденсаторы, сенсоры-актюаторы, устройства сбора и запасания побочной энергии (energy harvesting systems) [1-8]. В связи с этим усилия многих исследователей сконцентрированы на способах формирования слоев функциональных материалов на поверхности полимерных пьезопленок. Однако существующие методы и подходы к изготовлению полимерных пьезопленок в основном ориентированы на получение „гладких“ непористых пленок ПВДФ методами экструзии расплава или отливанием из растворов с последующей ориентацией, металлизацией и поляризацией в электрическом поле высокого напряжения. Проблема при формировании композиционных систем на базе пьезопленок ПВДФ состоит в том, что „гладкие“ пленки имеют низкую адгезию к электродным или функциональным материалам (включая большинство полимерных и низкомолекулярных покрытий). Существенно, что распространенные методики нанесения электродов на поверхности пленок относятся к затратным и/или трудоемким малопроизводительным процессам, которые имеют ограничения при получении пленок большого размера.
ПВДФ $\left(-\mathrm{CF}_{2}-\mathrm{CH}_{2}-\right)_{n}$ является аморфно-кристаллическим полимером $\left(T_{g} \approx-40^{\circ} \mathrm{C}, T_{m}=167-177^{\circ} \mathrm{C}\right)$ и относится к группе линейных гибкоцепных полимеров. Было показано [9-11], что в определенных условиях фильерной вытяжки расплава он способен образовывать ориентированную надмолекулярную структуру, состоящую из стопок плоских ламеллярных кристаллитов, расположенных перпендикулярно направлению преимущественной ориентации цепей макромолекул (оси $c$ ). Благодаря такой структуре для ПВДФ удалось реализовать один из наиболее эффективных методов получения полимерных микропористых пленок и волокон в ходе четырехстадийного процесса, включающего экструзию расплава, изометрический отжиг экструдированных образцов, их одноосное растяжение и термофиксацию. Было установлено [10], что пленки ПВДФ, полученные экструзией расплава при кратности фильерной вытяжки 15-55 и подвергнутые изометрическому отжигу при температуре, предельно близкой к температуре плавления полимера, демонстрируют деформационное поведение „жесткоэластического“ типа, т.е. образцы характеризуются сочетанием высокого модуля упругости и способности к большим обратимым деформациям. При одноосном растяжении отожженных пленок в них появляются открытые к поверхности и замкнутые в объеме образца микропоры. Образование в процессе деформации образца открытых пор приводит к формированию развитой рельефной поверхности, которая обеспечивает высокую адгезию при использовании этих пленок в качестве подложек для формирования функциональных слоев таких компонентов, как электропроводящие полимеры: полипиррол и полианилин [12].

Кристаллическая структура ПВДФ характеризуется наличием по крайней мере двух полиморфных моди- 
фикаций (в основном $\alpha$ - и $\beta$-форм; $\gamma$-форма встречается редко и в небольших количествах), причем образцы демонстрируют сильный пьезоэффект при условии высокого содержания сильнополярных кристаллитов $\beta$-модификации $[13,14]$. В то же время пленки гомополимера винилиденфторида кристаллизуются из расплава в слабополярной $\alpha$-форме, а полиморфный переход от $\alpha$ - к $\beta$-модификации может быть эффективно реализован с помощью деформационных воздействий при ориентационной вытяжке или под высоким давлением [13]. В связи с этим разработка подхода, который позволяет сформировать в микропористых пленках ПВДФ высокое содержание пьезоактивных кристаллитов $\beta$-формы, является важной и актуальной задачей с точки зрения практического использования пьезоактивных образцов ПВДФ. Цель настоящей работы - установить факторы, определяющие характеристики микропористой структуры пленок ПВДФ, и исследовать их влияние на содержание кристаллитов $\beta$-формы, электрическую прочность и пьезомодуль полученных образцов.

\section{2. Объекты и методы исследования}

Использовались гранулы ПВДФ коммерческой марки Kynar-720 (США) с молекулярной массой $1.9 \cdot 10^{5}$, температурой плавления $168^{\circ} \mathrm{C}$ и плотностью $1.78 \mathrm{~g} / \mathrm{cm}^{3}$. Пористые пленки получались в процессе, включающем стадии экструзии расплава ПВДФ, изометрического отжига экструдированных пленок, одноосного растяжения отожженных образцов (стадия порообразования) и термической стабилизации сформированной пористой структуры. Экструзия расплава полимера проводилась на лабораторной установке „Sсатіа“ (Франция) через плоскощелевую фильеру при температуре $200^{\circ} \mathrm{C}$ и кратности вытяжки 15, которая задавалась соотношением скорости подачи расплава и скорости приема пленки на принимающих валках.

Кристаллизация расплава проходила в охлаждаемой воздушным потоком зоне выхода расплава из фильеры. Экструдированная пленка (ее толщина составляла $60 \mu \mathrm{m}$ ) отжигалась в изометрических условиях (при фиксации концов образца) в течение часа при температуpe, близкой к температуре плавления полимера $\left(167^{\circ} \mathrm{C}\right)$.

Одноосное растяжение отожженных пленок осуществлялось на воздухе в направлении ориентации со скоростью $50 \% / \mathrm{min}$ в интервале температур растяжения $T_{d}$ от 25 до $75^{\circ} \mathrm{C}$. Для приготовления пористых пьезопленок использовались образцы с отношением базовой длины к ширине $1: 1(50 \times 50 \mathrm{~mm})$. Степень одноосного растяжения $\varepsilon_{d}$ варьировалась от 150 до $375 \%$. Точное определение значений степени растяжения проводилось по разметке, нанесенной на образец.

Для предотвращения усадки после снятия растягивающего напряжения пленки подвергались термической стабилизации в изометрических условиях в течение $1 \mathrm{~h}$ при температуре $100^{\circ} \mathrm{C}$.
Кривые напряжение-деформация получались при одноосном растяжении образцов размером $5 \times 50 \mathrm{~mm}$ со скоростью 100\%/min на разрывной машине 2166 Р-5 (Иваново, Россия).

Общая пористость образцов измерялась гравиметрическим методом и рассчитывалась по формуле

$$
P=\left[\left(\rho-\rho_{p}\right) / \rho\right] \cdot 100 \%,
$$

где $\rho-$ плотность монолитной пленки ПВДФ $\left(1.78 \mathrm{~g} / \mathrm{cm}^{3}\right), \rho_{p}$ - плотность пористой пленки.

Исследования методом широкоуглового рентгеновского рассеяния проводились на установке ДРОН 2.0 („Буревестник“, Санкт-Петербург, Россия) с использованием $\mathrm{Cu} K_{\alpha}$-излучения. Съемка производилась „на просвет ${ }^{6}$. Для определения характера и степени ориентации образцов получали азимутальные кривые интенсивности рефлекса (110). В работе [14] было установлено, что микропористые пленки ПВДФ содержат смесь кристаллитов $\alpha$ - и $\beta$-форм. Процентное содержание $\alpha$ - и $\beta$-форм рассчитывалось с помощью соотношения интенсивностей соответствующих меридиональных рефлексов (пики при $2 \theta=18$ и $20^{\circ}$ соответственно).

Для металлизации микропористых пленок ПВДФ использовался эвтектический сплав индий-галлий-олово, который наносился вручную путем притирания жидкого металла к предварительно обезжиренной поверхности образцов. Для сравнения эффективности металлизации были приготовлены пленки ПВДФ с электродами, нанесенными „традиционным“ способом вакуумного напыления алюминия.

Поляризация пленок ПВДФ проводилась контактным методом термополяризации [15]: к противоположным металлизированным поверхностям пленки прикладывали постоянное напряжение $E_{\text {pol }}$ и выдерживали $60 \mathrm{~min}$ при заданной температуре $T_{\text {pol }}\left(50,70\right.$ и $\left.90^{\circ} \mathrm{C}\right)$, после чего пленку охлаждали до комнатной температуры при включенном электрическом поле. Максимально возможное напряжение поляризации определяли по измерениям электрической прочности полученных пленок (напряженности поля при пробое образца $E_{f}$ ). Для этого металлизированные пленки выдерживали в электрическом поле при заданной температуре, постепенно увеличивая напряженность до пробоя, который фиксировали по характерному хлопку. Эксперимент повторялся не менее трех раз для каждого образца. При испытании на пробой не были учтены „краевые эффекты“, вследствие чего полученные значения $E_{f}$ должны рассматриваться как заниженные.

Пьезомодуль $d_{31}$ измерялся статическим методом приложения растягивающего усилия к поляризованным пленкам. Механическая нагрузка вдоль оси ориентации образца задавалась в диапазоне усилий от 5 до $20 \mathrm{~N}$. С помощью потенциостата Р-30 („Элинс“, Черноголовка, Россия) измерялась разность потенциалов, возникающая на контактных электродах образца при его дефор- 
мации. Пьезомодуль $d_{31}$ рассчитывался по формуле [15]

$$
d_{31}=\frac{C \Delta U B}{A \Delta F}
$$

где $C=C_{x}+C_{0} ; \Delta U=U_{2}-U_{1}, \Delta F=F_{2}-F_{1}, C_{x}-$ емкость образца $[\mathrm{F}], C_{0}-$ емкость образцового конденсатора $(1 \mu \mathrm{F}), A-$ площадь электродов $\left[\mathrm{cm}^{2}\right], B-$ площадь поперечного сечения пленки $\left[\mathrm{cm}^{2}\right], F-$ pacтягивающее усилие $[\mathrm{N}], U-$ электрическое напряжение $[\mathrm{V}], U_{1}$ и $U_{2}$ - электрическое напряжение при $F_{1}$ и $F_{2}$ соответственно.

\section{3. Результаты и обсуждение}

3.1. Развитие пористой структуры и полиморфные трансформации при растяжении отожженных пленок ПВДФ. При одноосном растяжении отожженных пленок ПВДФ в направлении экструзии наблюдается помутнение исходно полупрозрачных пленок и постепенное окрашивание образцов в молочно-белый цвет по мере растяжения, что свидетельствует о формировании микропористой структуры. Образование пор начинается уже при малых степенях деформирования, что визуально наблюдается по началу помутнения пленок, которое происходит вследствие рассеяния света на стенках образовавшихся пор. Нарастание помутнения по мере увеличения степени растяжения свидетельствует о повышении общей пористости образцов.

Кривые напряжение-деформация (рис. 1) показывают, что на процесс структурообразования оказывает значительное влияние температура, при которой проводится растяжение. Как видно из рис. 1, увеличение температуры вытяжки $T_{d}$ с 25 до $75^{\circ} \mathrm{C}$ приводит к возрастанию удлинения при разрыве с 600 до $1100 \%$ и небольшому росту разрывного напряжения с 55 до $64 \mathrm{MPa}$. В то же время наблюдается снижение предела текучести

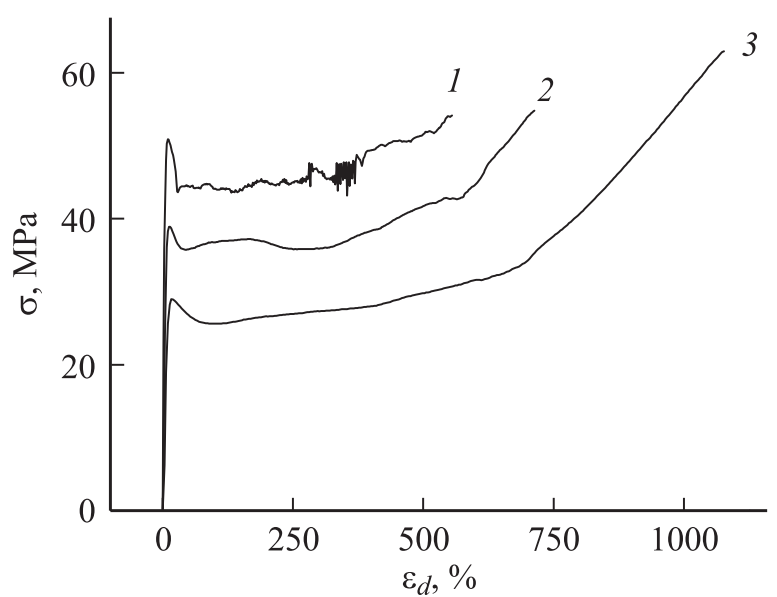

Pис. 1. Кривые напряжение-деформация для отожженных пленок ПВДФ, полученные при значениях температуры растяжения $25(1), 50(2)$ и $75^{\circ} \mathrm{C}(3)$.

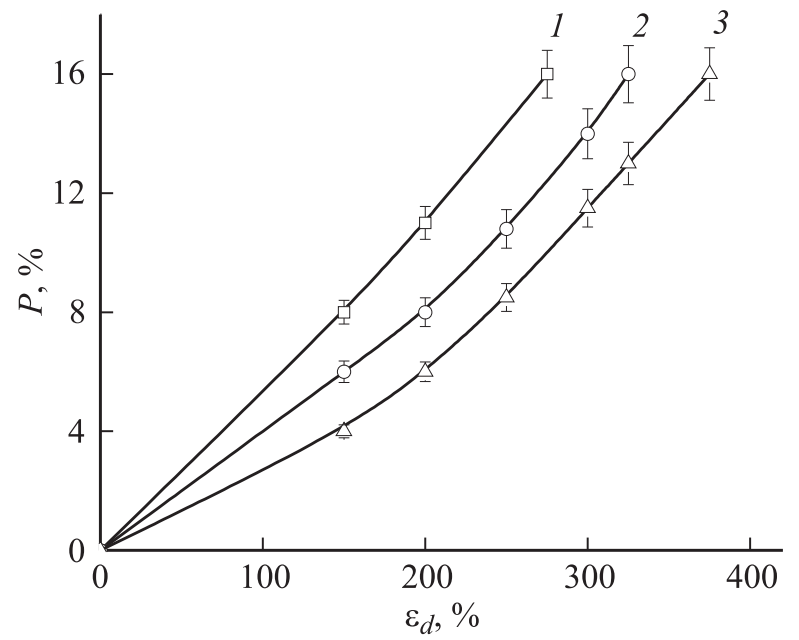

Рис. 2. Зависимость общей пористости $P$ пленок ПВДФ от степени растяжения $\varepsilon_{d}$ при температурах вытяжки 25 (1), $50(2)$ и $75^{\circ} \mathrm{C}(3)$.

с 50 до $28 \mathrm{MPa} \mathrm{и} \mathrm{модуля} \mathrm{упругости} \mathrm{образцов} \mathrm{с} 2310$ до $1890 \mathrm{MPa.} \mathrm{Следует} \mathrm{отметить,} \mathrm{что} \mathrm{растяжение} \mathrm{пленки}$ при $T_{d}=25^{\circ} \mathrm{C}$ сопровождается множественным шейкообразованием, что отражается на неравномерном ходе кривой после достижения предела текучести. Повышение температуры растяжения способствует достижению большей стабильности процесса и равномерности структуры получаемых образцов. В то же время растяжение пленок при температуре, превышающей $75^{\circ} \mathrm{C}$, не сопровождается порообразованием, что связано с размораживанием молекулярной подвижности цепей в околокристаллических областях при достижении релаксационного $\alpha_{c}$-перехода (пика на релаксационной кривой), который для ПВДФ находится в диапазоне $80-100^{\circ} \mathrm{C}$ [9]. Таким образом, температуры растяжения $25<T_{d}<75^{\circ} \mathrm{C}$ являются оптимальными с точки зрения стабильности процесса порообразования, а проведение процесса при $T_{d}$, близких к $75^{\circ} \mathrm{C}$, позволяет повысить прочность и эластичность получаемых пористых образцов.

Измерения общей пористости показали, что эта величина для образцов ПВДФ возрастает с увеличением степени растяжения (рис. 2). Максимальное значение общей пористости наблюдается при достижении предельных степеней растяжения и составляет $16 \%$. При увеличении температуры растяжения зависимости смещаются в область бо́льших значений деформации.

Возрастание общей пористости при увеличении степени растяжения $\varepsilon_{d}$ происходит вследствие роста числа и размеров пор, что приводит к их слиянию и появлению открытых к поверхности пор, а также образованию сквозных каналов по механизму перколяции, которая, согласно [16,17], происходит при значениях общей пористости выше $25-30 \%$. При возникновении открытых пор и сквозных каналов выход напряжения, накапливающегося в образце при растяжении, приводит к изменению структуры поверхности пленок: от гладкой 


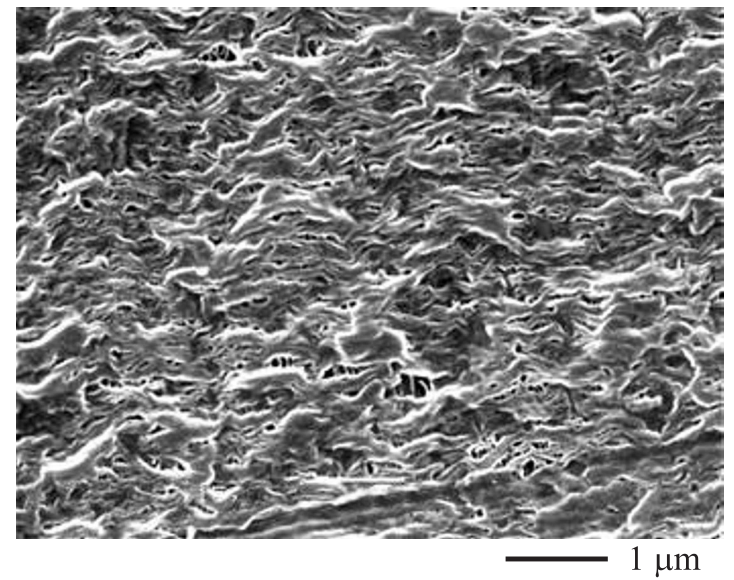

Рис. 3. Поверхность пористого образца ПВДФ $\left(T_{d}=50^{\circ} \mathrm{C}\right.$, $\left.\varepsilon_{d}=300 \%\right)$, полученная методом сканирующей электронной микроскопии при увеличении 15000 (направление ориентации пленки - по вертикали).

для исходных образцов к рельефной с чередованием выступов и впадин для пористых пленок. Понятно, что при общей пористости $16 \%$ сквозные каналы не образуются, однако в результате наличия открытых пор поверхность пленок характеризуется сильно выраженной рельефностью (рис. 3). На представленной микрофотографии видны сплошные участки (закристаллизованный полимер), разделенные порами с размерами порядка до $0.5 \mu \mathrm{m}$. Поры имеют вытянутую поперек направления ориентации форму, а через них проходят расположенные в направлении ориентации фибриллоподобные тяжи, соединяющие края пор, т. е. соседние участки закристаллизованного ламеллярного материала.

Методом рентгеновского рассеяния было исследовано влияние условий одноосного растяжения отожженных образцов на содержание кристаллической $\beta$-модификации в пористых пленках (рис. 4). Как показали проведенные исследования, экструдированные и отожженные пленки ПВДФ характеризуются наличием рефлексов, относящихся исключительно к кристаллитам $\alpha$-формы. Однако для микропористых пленок уже при степенях растяжения $\varepsilon_{d}=150-200 \%$ в процессе порообразования наблюдается интенсивный $\alpha \rightarrow \beta$-переход. В этом диапазоне деформаций содержание кристаллитов $\beta$-формы превышает 70\% при всех температурах растяжения. При температуре $25^{\circ} \mathrm{C}$ с возрастанием $\varepsilon_{d}$ свыше $150 \%$ увеличения доли $\beta$-формы не происходит (рис. 4,a), в то время как для пленок, растянутых при 50 и $75^{\circ} \mathrm{C}$, доля $\beta$-формы растет с увеличением $\varepsilon_{d}$ вплоть до $300 \%$ и достигает 83 и $80 \%$ соответственно (рис. $4, b, c)$. Отметим, что растяжение образцов до близких к предельным значениям удлинений (предразрывных) приводит к небольшому снижению содержания кристаллитов $\beta$-формы. Последнее обстоятельство может быть связано с частичным разрушением сильно ориентированных $\beta$-кристаллитов при термофиксации в изо- метрических условиях, которая проводится при $100^{\circ} \mathrm{C}$ сразу после стадии одноосного растяжения образцов.

Как следует из рис. 2 и 4, при растяжении отожженных пленок ПВДФ процесс $\alpha \rightarrow \beta$-превращения происходит одновременно с процессом порообразования. Отметим, что сложность в экспериментальном определении условий получения микропористых пленок ПВДФ с высоким содержанием кристаллитов $\beta$-формы связана
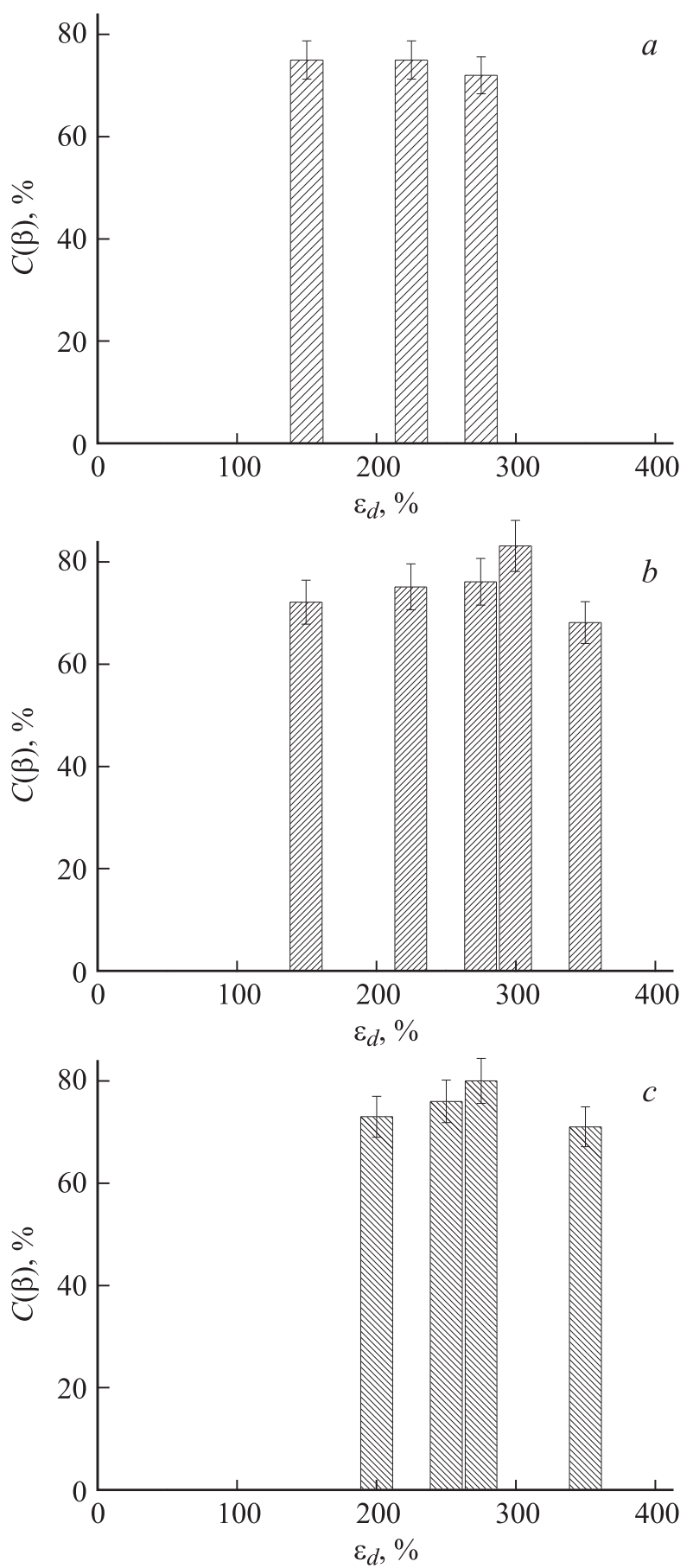

Рис. 4. Зависимость содержания пьезоактивной кристаллической фазы ( $\beta$-фазы) $C(\beta)$ от степени растяжения $\varepsilon_{d}$ для температур растяжения $T_{d}=25(a), 50(b)$ и $75^{\circ} \mathrm{C}(c)$. 
с конкурирующим характером процессов порообразования и полиморфного превращения $[9,10]$. Это связано с тем, что ориентационное воздействие, инициирующее $\alpha \rightarrow \beta$-превращение, приводит также к перестройке надмолекулярной структуры, что препятствует эффективному раздвижению плоскопараллельных ламеллярных кристаллитов, сформированных на стадии экструзии и изометрического отжига, и образованию пор между ними.

3.2. Электрическая прочность и пьезоэлектрический модуль поляризованных микропористых пленок ПВДФ. Электрическая прочность полимера, обладающего пьезоэлектрическими свойствами, играет важную практическую роль при проведении контактной термополяризации, особенно в условиях высоковольтной обработки микропористых образцов, поскольку ее значение накладывает ограничение на предельно возможное напряжение поляризации. Как видно из рис. 5, электрическая прочность образцов повышается с увеличением температуры растяжения. В то же время степень растяжения пленок не влияет на их электрическую прочность вплоть до значений $230-270 \%$, а затем наблюдается заметное понижение напряжения пробоя. Очевидно, что характер этих зависимостей находится в корреляции с зависимостью общей пористости $P$ от $\varepsilon_{d}$ (рис. 2) в связи с тем, что увеличение $P$ приводит к увеличению вероятности электрического пробоя. Отметим, что пробою пленки может сопутствовать проникновение жидкого металла в открытые к поверхности пленки поры.

Важнейшими параметрами процесса контактной термополяризации являются температура поляризации и напряженность электрического поля. Об эффективности проведения поляризации пленок ПВДФ можно судить по значению пьезомодуля поляризованных образцов. Как видно из табл. 1 , пьезомодуль $d_{31}$ возрастает и с увеличением значения напряженности электрического поля $E_{\mathrm{pol}}$, и с увеличением температуры поляризации $T_{\text {pol. }}$. Однако следует отметить, что повышение обоих параметров приводит к увеличению вероятности электрического пробоя.

Как видно из рис. 6, увеличение степени растяжения образцов $\varepsilon_{d}$ в процессе порообразования приво-

Таблица 1. Значения пьезомодуля $d_{31}(\mathrm{pC} / \mathrm{N})$ для пленки ПВДФ, полученной при $T_{d}=50^{\circ} \mathrm{C}$ и $\varepsilon_{d}=300 \%$, в зависимости от температуры поляризации $T_{\mathrm{pol}}$ и напряженности электрического поля $E_{\mathrm{pol}}$

\begin{tabular}{c|r|r|r|r|c}
\hline \multirow{2}{*}{$T_{\mathrm{pol}},{ }^{\circ} \mathrm{C}$} & \multicolumn{5}{|c}{$E_{\mathrm{pol}}, \mathrm{V} / \mu \mathrm{m}$} \\
\cline { 2 - 6 } & 55 & 60 & 65 & 70 & 75 \\
\hline 50 & 1 & 1 & 5 & 12 & 14 \\
70 & 10 & 14 & 17 & 18 & $*$ \\
90 & 15 & 17 & $*$ & $*$ & $*$
\end{tabular}

* - образец не мог быть получен из-за недостаточной электрической прочности.

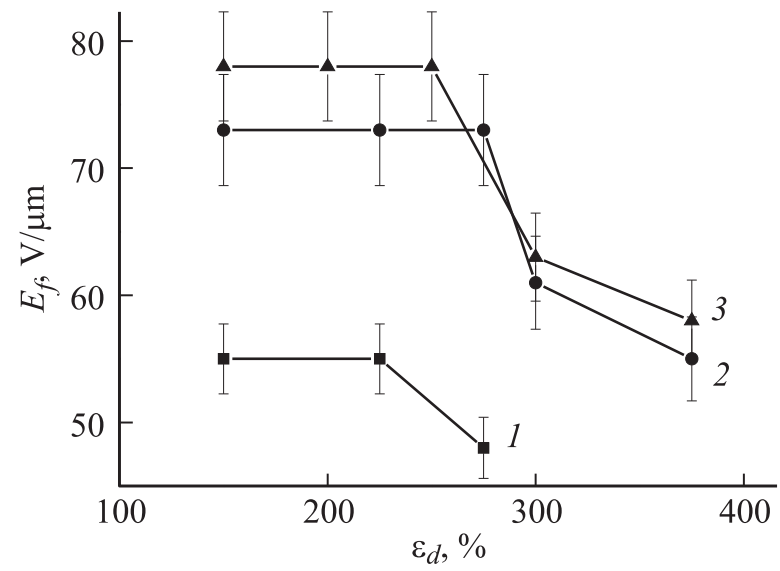

Рис. 5. Зависимость электрической прочности $E_{f}$ микропористых пленок ПВДФ от степени растяжения $\varepsilon_{d}$ для образцов, полученных при $T_{d}=25(1), 50(2)$ и $75^{\circ} \mathrm{C}(3)$. Температура эксперимента (измерения электрической прочности) $70^{\circ} \mathrm{C}$.

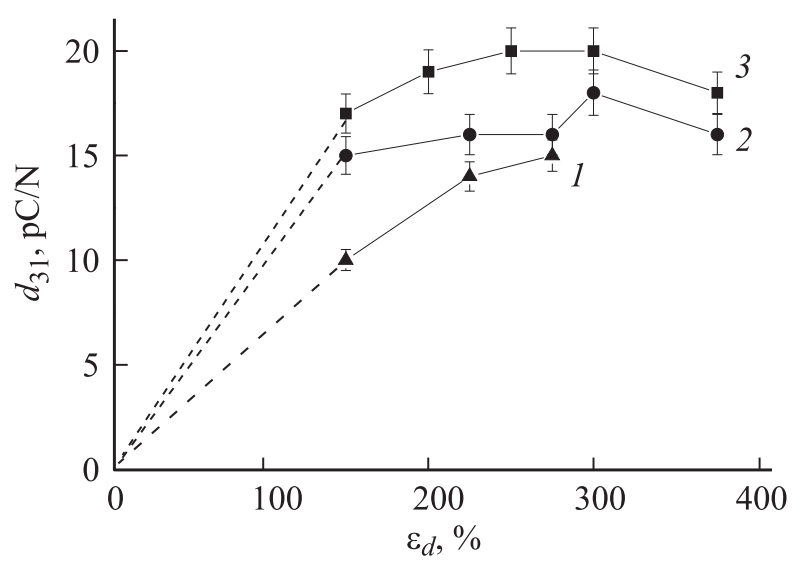

Рис. 6. Зависимость пьезомодуля $d_{31}$ пористых пленок ПВДФ от $\varepsilon_{d}$ при температурах растяжения 25 (1), 50 (2), $75^{\circ} \mathrm{C}(3)$. Поляризация образцов проводилась при значении $E_{\mathrm{pol}} \approx 0.9 E_{f}$ и $T_{\mathrm{pol}}=70^{\circ} \mathrm{C}$.

дит к непрерывному возрастанию пьезомодуля вплоть до значений $\varepsilon_{d}$, соответствующих наибольшему содержанию $\beta$-фазы (рис. 4). Наиболее высокое значение $d_{31}=20$ pC/N было достигнуто для образцов, вытянутых при $75^{\circ} \mathrm{C}$. При понижении температуры растяжения до $25^{\circ} \mathrm{C}$ значения пьезомодуля не превышают $15 \mathrm{pC} / \mathrm{N}$. Более пористые образцы, полученные при $\varepsilon_{d}>300 \%$, обладают меньшими значениями пьезомодуля, что может быть связано с невозможностью повысить напряжение поляризации вследствие меньшего уровня электрической прочности. Эта проблема может быть решена с помощью перехода к бесконтактному способу поляризации пьезопленок - коронной поляризации.

Известно [18], что тип электрода может оказывать существенное влияние на пьезоэлектрические характеристики ПВДФ. Чтобы исследовать этот эффект для полученных в настоящей работе пленок ПВДФ, была 
Таблица 2. Влияние типа электрода на величину и стабильность значения пьезомодуля $d_{31}(\mathrm{pC} / \mathrm{N})$ микропористых пленок ПВДФ

\begin{tabular}{l|c|c|c|c}
\hline \multirow{2}{*}{$\begin{array}{c}\text { Электродный } \\
\text { слой }\end{array}$} & \multicolumn{3}{|c}{ Время после поляризации образца ПВДФ } \\
\cline { 2 - 5 } & $\begin{array}{c}\text { Сразу после } \\
\text { поляризации }\end{array}$ & $\begin{array}{c}\text { Спустя } \\
\text { сутки }\end{array}$ & $\begin{array}{c}\text { Через } \\
\text { месяц }\end{array}$ & $\begin{array}{c}\text { Через шесть } \\
\text { месяцев }\end{array}$ \\
\hline Алюминий & 24.0 & 21.6 & 19.0 & 19.0 \\
Сплав In-Ga-Sn & 18.0 & 16.1 & 14.5 & 14.4 \\
& & & &
\end{tabular}

определена их поляризуемость при нанесении слоев жидкого металла на образцы и проведено сравнение результатов поляризации пленок, приготовленных при $T_{d}=50^{\circ} \mathrm{C}$ и $\varepsilon_{d}=300 \%$, с электродными контактами из сплава индий-галлий-олово и алюминиевого слоя. Как видно из табл. 2, образцы, металлизированные алюминием, показали более высокое значение пьезомодуля, т.е. в этом случае поляризация прошла более эффективно. Отметим, что за первые сутки хранения образцов при комнатных условиях величина пьезомодуля понижалась на $\sim 10 \%$ независимо от типа используемого электрода, однако в дальнейшем образцы демонстрировали высокую стабильность поляризации во времени.

\section{4. Заключение}

Предлагаемый в работе способ получения микропористых пьезопленок ПВДФ позволяет сформировать образцы с высокими значениями общей пористости и содержания пьезоактивной кристаллической $\beta$-фазы. Исследовано влияние параметров процесса приготовления образцов (степени растяжения и температуры растяжения при порообразовании) на их структуру (общую пористость, содержание пьезоактивной $\beta$-модификации) и пьезоэлектрические свойства (электрическую прочность и пьезомодуль $\left.d_{31}\right)$. Показано, что при оптимальных условиях получения пористые пьезопленки имеют общую пористость 16\% при доле $\beta$-фазы в кристаллической части образца свыше $80 \%$. Пьезомодуль таких образцов достигает $18-20$ pC/N. Установлено, что повышение пористости приводит к снижению электрической прочности, что накладывает ограничение на практическое применение метода контактной поляризации для пьезоактивных микропористых пленок ПВДФ. Преимуществом предложенного в работе способа получения полимерных пьезопленок является возможность изготовления образцов пьезоэлемента большого размера. Важно отметить, что в микропористых пьезопленках сохраняется прочность и эластичность, присущая известным пленочным материалам из ПВДФ. Сочетание пьезоэлектрических свойств и микропористой структуры в данных пленках ПВДФ делает предложенный способ их получения перспективным для производства электроактивных композиционных материалов с целью их использования в разного рода системах накопления и запасания энергии (пьезоактюаторах, пьезосуперконденсаторах, пьезобиосенсорах и т.д.).

Авторы выражают благодарность Н.Н. Сапрыкиной (ИВС РАН) за проведение исследований методом сканирующей электронной микроскопии.

\section{Список литературы}

[1] X. Xue, P. Deng, Sh. Yuan, Yu. Nie, B. He, L. Xing, Y. Zhang. Energy Environ. Sci. 6, 2615 (2013).

[2] H.S. Kim, J.-H. Kim, J. Kim. J. Int. J. Precis. Eng. Manuf. 12, 1129 (2011).

[3] M. Lee, Ch.-Y. Chen, S. Wang, S.N. Cha, Y.J. Park, J.M. Kim, L.-J. Chou, Zh.L. Wang. Adv. Mater. 24, 1759 (2012).

[4] X. Lu, Q. Guo, Zh. Xu, W. Ren, Z.-Y. Cheng. Sensors Actuators A 179, 32 (2012).

[5] P. Incio, C.J. Dias, J.N. Marat-Mendes. Key Eng. Mater. 230, 491 (2002).

[6] B.J. Hansen, Y. Liu, R. Yang, Zh.L. Wang. Acs Nano 4, 3647 (2010).

[7] R. Song, H. Jin, X. Li, L. Fei, Y. Zhao, H. Huang, H.L.W. Chan, Y. Wang, Y. Chai. J. Mater. Chem. A 3, 14963 (2015).

[8] S. Siddiqui, D.-I. Kim, L.Th. Duy, M.Tr. Nguyen, Sh. Muhammad, W.-S. Yoon, N.-Eu. Lee. Nano Energy 15, 177 (2015).

[9] I.Yu. Dmitriev, V. Bukošek, V.K. Lavrentyev, G.K. Elyashevich. Acta Chim. Slov. 54, 784 (2007).

[10] И.Ю. Дмитриев, И.С. Курындин, Н.Н. Сапрыкина, В.К. Лаврентьев. Изв. вузов. Технология лег. пром-ти $\mathbf{1 7}$ 15 (2012).

[11] Е.А. Карпов, В.К. Лаврентьев, Е.Ю. Розова, Г.К. Ельяшевич. Высокомолекуляр. соединения А 37, 2035 (1995).

[12] И.Ю. Дмитриев, И.С. Курындин, Г.К. Ельяшевич. Способ получения полимерных пьезопленок со слоями электропроводящих полимеров. Патент РФ по заявке № 2016131928 от 04.08.2016 г.

[13] V.V. Kochervinskii, N.V. Kozlova, A.Y. Khnykov, M.A. Shcherbina, S.N. Sulyanov, K.A. Dembo. J. Appl. Polym. Sci. 116, 695 (2010).

[14] И.Ю. Дмитриев, В.К. Лаврентьев, Г.К. Ельяшевич. Высокомолекуляр. соединения А 48, 447 (2006).

[15] Г.А. Лущейкин. Полимерные пьезоэлектрики. Химия, М. (1990). $176 \mathrm{c}$.

[16] И.С. Курындин, В.К. Лаврентьев, V. Bukošek, Г.К. Ельяшевич. Высокомолекуляр. соединения А 57, 497 (2015).

[17] D. Stauffer, A. Aharony. Introduction to percolation theory. Taylor and Francis, London (1994). 91 p.

[18] В.В. Кочервинский, Е.В. Чубунова, Ю.Ю. Лебединский, Н.А. Шмакова. Высокомолекуляр. соединения А 53, 1729 (2011). 